\title{
Inconsciente e Cotidiano na Prática da Atenção Psicossocial em Saúde Mental ${ }^{1}$
}

\author{
Nilson Gomes Vieira Filho ${ }^{2}$ \\ Universidade Federal do Amazonas \\ Miriam Debieux Rosa \\ Universidade de São Paulo
}

\begin{abstract}
RESUMO - O objetivo deste artigo é analisar as concepções sobre o inconsciente ligadas ao cotidiano da prática terapêutica de rede, como contribuição à clínica em saúde mental. A pesquisa participante foi realizada em um Centro de Atenção Psicossocial (CAPS) na cidade de São Paulo. Os resultados mostraram as concepções mais frequentes: o inconsciente como inconsciência, o inconsciente como desconhecimento e o inconsciente como método de escuta do sujeito e das relações na instituição. Demonstram uma flexibilidade teórica que pode permitir articulações complexas nas diversas intervenções no cotidiano da equipe referentes às subjetividades e saberes sobre o inconsciente, psicanalíticos ou não. Conclui-se que a elucidação desse saber prático sobre o inconsciente contribui para o aprofundamento dessa temática no campo da reforma psiquiátrica.
\end{abstract}

Palavras-chave: inconsciente; cotidiano; atenção psicossocial; saúde mental.

\section{Unconscious and Everyday Life in the Practice of Psychosocial Attention in Mental Health}

\begin{abstract}
The goal of this article is to analyze the conceptions about the unconscious connected with the everyday life of the therapeutic practice network, as a contribution to the mental health clinical approach. The participant research took place in a Psychosocial Care Center at São Paulo countryside. The results showed the most frequent conceptions: unconscious as unconsciousness, unconscious as ignorance, and unconscious as a method to listen to the subject and to the relationships in the institution. Those results demonstrate a theoretical flexibility that allows complex articulations in diverse interventions in the everyday life of the team referring to subjectivities and knowledge about unconscious, related or not to psychoanalysis. It is concluded that practical knowledge elucidation about unconscious contributes to this subject deepening in the psychiatric reform.
\end{abstract}

Keywords: unconscious; everyday life; psychosocial care; mental health.

O inconsciente descrito por Freud (1900/1976) em $A$ interpretação dos sonhos foi um marco que abriu várias polêmicas teóricas. A principal foi o deslocamento da posição cartesiana, centralizada na razão/lógica como a mais alta esfera do funcionamento humano em contraposição aos instintos, para ressaltar a importância da sexualidade no dimensionamento da existência, do sentido da vida. A relação enigmática entre o respeitável Dr. Jekyll e seu diabólico "alter-ego" Edward Hyde, na obra clássica de Stevenson (2003), é emblemática de uma divisão entre o sujeito da lógica alinhavada com a moral e o bem ou o sujeito dominado pelos excessos. Diferente dessa concepção, a sexualidade, no sentido freudiano, concebe o infantil, presente no adulto, pulsando na direção do desejo. Desejo que se manifesta como força direcionadora do inconsciente, gerando atos que podem ser posteriormente explicados ou justificados pela razão.

1 Agradecemos a colaboração da psicóloga Elaine Vidote, da terapeuta ocupacional Tereza C. Macedo Vidal e do psiquiatra Sebastião Carlos Coutinho nas discussões deste artigo.

2 Endereço para correspondência: Faculdade de Psicologia (UFAM). Av. General Rodrigo Otávio Jordão Ramos, 3000. Setor Norte. Campus Universitário. Manaus, AM. CEP 69077-000.E-mail: ngovi@uol. com.br; debieux@terra.com.br.
Nessa perspectiva, estabelece-se a diferença entre o conhecimento do Eu e o saber do inconsciente, assim como a via de acesso ao inconsciente pela transferência. O saber, a criação de novos saberes, só é instaurado por meio da relação de pelo menos dois "inconscientes", isto é, por um sujeito que escuta o outro. Essas concepções foram refeitas e reconsideradas na psicanálise. Encontramos em Freud e em outros autores psicanalistas modos distintos de emprego do conceito de inconsciente que não nos cabe estender.

Diferente do que se concebe no senso comum, o inconsciente apontado pela psicanálise não é intrapsíquico, nem adjetivado por características x ou y, nem do bem ou do mal, mas rege o sujeito constituído a partir do laço com o outro, laço discursivo, recriado a cada relação e que, dependendo da modalidade de laço social, pode fazer surgir o pior ou o melhor. Dessa forma, articula-se ao social e ao político, pois provoca um abalo na convicção do individualismo e apresenta outra ética - a de um sujeito que abarca a potência do desejo e que faz valer o saber criativo para além da obediência das regras impostas como conformismo social (Rosa, Carignato \& Berta, 2006).

A consequência para a área da saúde mental é a suspensão do caráter de doença da histeria e a consideração de seus sintomas como uma das modalidades de expressão do 
sofrimento na relação com o outro. O sintoma ganha novo estatuto, de satisfação substitutiva, porta caráter conservador como solução de compromisso, mas estando em contínuo deciframento pode indicar aproximações do desejo. A divisão entre o indivíduo e a sociedade também é redimensionada. $\mathrm{O}$ sintoma aparece como mensagem da conflitualidade libidinal, mas também familiar, social e política. Assim, a leitura do laço social permite a redescoberta de uma conflitualidade ampliada nas dinâmicas transferenciais e nas ambivalências e contradições das relações humanas do sujeito.

A clínica em saúde mental se constrói e reconstrói na dinâmica do trabalho terapêutico em rede social e de um cotidiano influenciado pelo contexto histórico da reforma psiquiátrica (Vieira Filho \& Nóbrega, 2004). Trata-se essencialmente de uma clínica do sujeito-social, isto é, uma clínica do sujeito em situação sociocultural na qual perpassa uma dinâmica de redes sociais e instituições. O que supõe "a recusa de isolar o sujeito, mas a necessidade de escutá-lo em situação, em luta consigo mesmo, com os outros, nos contextos sociais e culturais, em uma história individual, coletiva, evoluindo na dinâmica da relação" (Barus-Michel, 1997, p. 7). Essa clínica possibilita uma leitura do laço social (Barus-Michel, 1991) ligada à perspectiva de complexidade e que engloba, portanto, diversos registros (subjetividade, relacional, corporal etc) em seus procedimentos e análises.

O objetivo principal deste artigo é analisar a emergência de concepções sobre o inconsciente ligadas ao cotidiano da prática terapêutica de um Centro de Atenção Psicossocial (CAPS-II), para adultos, no município paulista, no sentido de contribuir para a construção de uma clínica em saúde mental e em rede social. Entendemos que essa prática está marcada por saberes em transformação que não se acomodariam ou se "ajustariam" a uma aplicação de conhecimentos terapêuticos oriundos de contextos adversos ao da reforma psiquiátrica. Por isso, não se pretendeu corrigir esta ou aquela concepção emergente em termos normativos ou conceituais, mas estabelecer um diálogo entre o que era percebido e registrado no cotidiano e o que se podia contribuir para elucidar ou acrescentar a essa prática em invenção. O material coletado na observação participante realizada no referido Centro permitiu colocar em evidência várias concepções sobre o inconsciente e refletir sobre as mesmas.

\section{Método}

\section{Participantes e ambiente}

O campo investigado é um Centro de Atenção Psicossocial (CAPS-II), serviço substitutivo no processo de reforma psiquiátrica (Barreto, 2005), no município de São Paulo. Funciona internamente como uma coletividade terapêutica na qual todos os profissionais que aí trabalham participam de um modo ou de outro das ações de cuidados em saúde mental. Tanto as relações de cooperação entre profissionais e entre esses e os usuários são de tendência horizontal. As atividades de atendimentos e outras são geralmente discutidas nas reuniões diárias da equipe, sendo as discussões mais aprofundadas de casos clínicos feitas pelas equipes terapêuticas de referência dos usuários. A assembléia geral, incluindo todos os usuários e os diversos profissionais (e.g., médicos, psicólogos, assistentes sociais, porteiros, faxineiros), ocorre uma vez por semana, na qual é, sobretudo, ressaltada a participação ativa dos usuários na organização.

Os cuidados em saúde mental e em rede social realizados pela equipe multiprofissional (e.g., psicólogos, psiquiatras, terapeutas ocupacionais, assistentes sociais, enfermeiras, auxiliares de enfermagem) implicam um modo de atuação terapêutica no qual é valorizada a ação e a reflexão dos processos relacionais e comunicativos entre profissionais, usuários e pessoas ou grupo da rede de interações significativas desses últimos (e.g., familiares, vizinhos, agentes de saúde ). As conexões interinstitucionais formam uma rede integrada de serviços regionais, englobando hospital geral, outros CAPS (criança e adolescente, Álcool e Droga), centros de convivência e cooperativas, ambulatórios e postos de saúde - com ou sem Programa de Saúde da Família (PSF), ONGs, e assim por diante (Vieira Filho, 2006).

\section{Procedimento}

A observação participante, em psicologia clínica, aprovada pelo Comitê de Ética em Pesquisa da Secretaria de Saúde da Prefeitura de São Paulo, foi realizada no referido CAPSII, no qual o pesquisador participava de diversas atividades de cuidados à saúde mental, mas sem praticar intervenções clínicas. Enfrentar o cotidiano e a complexidade em pesquisa dessa natureza "significa aceitar o desafio de exercitar outras formas de apreender a realidade: formas de apreensão calcadas na multiplicidade de interpretações e produzidas no entrelaçamento das diferentes perspectivas, dos diferentes sujeitos, dos diferentes contextos da vida cotidiana" (Pérez, 2003 , p. 98). A cotidianidade demonstra o que é cotidiano e habitual e que não se reduz à repetitividade e à automatização e é também processo histórico e inventivo.

Observamos que o inconsciente não é habitualmente analisado ou verbalizado nas discussões da equipe multiprofissional e entende-se que seria difícil de fazê-lo com profissionais de formações diversas. As concepções sobre o inconsciente que buscamos conhecer são aquelas emergentes na prática do dia a dia dos profissionais e usuários do CAPS. Essas concepções tendem a aparecer pouco explícitas nos comentários desses indivíduos, apesar de influenciarem implicitamente o modo de atuação cotidiana, sobretudo, nas atividades terapêuticas grupais, isto é, grupo de contos (geralmente literários), grupo de verbalização (do sofrimento, delírio), grupo de cuidados sobre a medicação.

O material coletado reflete essa situação prática e se fez a partir de notas de campo sobre o cotidiano institucional vivenciado pelo autor principal desse trabalho. Utilizamos exemplos e alguns fragmentos de notas na análise que se segue. Foram também acrescidas a essas notas conversações com profissionais da equipe nos horários disponíveis, mas seguindo o ritmo de trabalho normal do CAPS. Isso quer dizer que as sequências dessas conversas de esclarecimento sobre o inconsciente eram geralmente interrompidas devido à necessidade de atendimento ao usuário, sendo mais adiante recomeçadas. Para melhorar a nossa compreensão pedimos 
a alguns profissionais que lessem nossas notas e fizessem comentários se achassem necessário.

\section{Resultados e Discussão}

Uma das concepções sobre o inconsciente mais freqüentes entre os usuários e profissionais não universitários é aquela do inconsciente como inconsciência. Exemplifica-se no dito "estar fora de si", situação na qual se diz que a pessoa está privada de consciência por encontrar-se em estado inconsciente, involuntário, mas geralmente temporário. Indica um sentido de perda ou alteração da consciência que levaria a pessoa a praticar um ato do qual não seria responsável. Essa concepção está associada também à ideia de perda de controle da situação visto que a pessoa não estaria em estado de "consciência normal".

Um usuário exemplifica o caso de uma convulsão epiléptica no qual a pessoa acometida perde subitamente a consciência e explica que essa perda não é um ato que depende da "vontade própria" dela. Outra usuária do CAPS afirmou que "se não é consciente é porque é inconsciente". Ela se referia a uma situação de acting out que vivenciou anos atrás em outro serviço de saúde mental inserido na lógica manicomial. Ao ver a televisão na sala, escutou a voz de seu pai (evangélico) dizendo que a "televisão era a perdição do cristão", entendida como “obra do inimigo de Deus". Furiosa, pegou um cabo de vassoura, bateu várias vezes no aparelho de TV, danificando-o. Em seguida, diz que foi internada em um hospital psiquiátrico. Esse relato ocorreu durante uma reunião de grupo de contos e nessa ocasião ela dizia que naquele momento de crise ela estava "fora de si" e por isso tinha sido internada. Em função da sua "inconsciência", ela se justificava diante do referido grupo dizendo que não deveria pagar por esse ato cometido no passado.

Essa usuária acrescentou ainda que a coordenadora do CAPS a faria pagar se ela danificasse uma TV e era por isso que nem se aproximava do local da TV. Parecia ter dúvidas quanto à "inconsciência" do ato anteriormente praticado na medida em que comparava a situação anterior, dentro de uma lógica manicomial, com o momento atual de hospitalidadedia vivenciado no CAPS. Essa coordenadora esclareceu posteriormente que, enquanto autoridade, ela representa a lei, estando, assim, no exercício do que se chama "função paterna", em psicanálise, colocando limites na conduta da usuária. Ela explicou que a usuária se coloca primeiramente em "outro lugar", um serviço do período anterior a atual reforma psiquiátrica, depois ela passa a falar de outro momento e espaço, o CAPS, que a responsabiliza por seus atos (não podia "quebrar as coisas") e a respeita como cidadã, construindo-se aí como sujeito.

Uma enfermeira esclareceu que falar sobre o inconsciente a fazia pensar na rotina diária que leva, às vezes, o profissional a "agir sem pensar" e a ter "atitudes impensadas", na medida em que não reflete sobre as ações que pratica. Ela diferencia este agir desta atitude. Este agir seria agir inconscientemente, mas a atitude seria algo mais sério, pois nesta o profissional estaria praticando ações sem querer refletir sobre elas. Daí a necessidade de uma parada para reavaliar o que ele faz nas ações vividas no CAPS. Quanto ao paciente, essa enfermeira considera que pode haver inconsciência ligada a patologias e a algum trauma. Disse ela que o paciente pode apresentar inconsciência daquilo que não tem crítica ou não ter consciência de discernimento ou mesmo ter perdido a capacidade de discernir. Diferencia 'ter consciência de' e 'ter capacidade de', que no segundo caso seria grave visto que o paciente não seria mais capaz de discernimento.

Tanto a enfermeira acima como uma auxiliar de enfermagem disseram que não faziam referência ao inconsciente psicanalítico. Essa auxiliar falou que "não dá para uma auxiliar trabalhar sobre o inconsciente, a gente é muito prática...". Em seguida, exemplificou que quando os pacientes estão "agitados", não pensam muito, ficam inconscientes de suas ações porque agem sem pensar, praticam ações impensadas. Quando voltam a ter consciência da situação, pensam no que fizeram e pedem desculpas. Segundo ela, esse estado de inconsciência seria gerado pela crise do paciente decorrente de um "estado de desarmonia energética entre o pólo positivo e o pólo negativo" (aqui ela se refere vagamente à medicina oriental). A volta ao "estado de harmonia" significa o fim da crise que é marcado por uma reação de reequilíbrio energético, isto é, o paciente volta a ficar consciente e com capacidade de reflexão.

Nesses comentários pode-se perceber que falar de inconsciente remete à produção de hipóteses sobre as dicotomias que habitam o sujeito, que a psicanálise destaca. Essas dicotomias aparecem seja como oposições de uma característica (e.g., em si versus fora de si, harmonia versus desarmonia, responsável versus irresponsável), seja como uma divisão mais radical entre modalidades de funcionamento (e.g., pensar e fazer, trabalho e ações impensadas), expressando que estão em registros diferentes. O curioso é que as propostas se invertem e o inconsciente pode estar do lado ora da ação irrefletida ora da reflexão. Assim, a auxiliar considera que ou se trabalha com o inconsciente, aqui tomado como pensar, ou se é prático.

Outra concepção geralmente presente entre alguns profissionais é a de inconsciente como desconhecimento. Disse um psiquiatra: "o que não se sabe... o desconhecido... algo que é desconhecido...". Esse desconhecimento seria da ordem do não sabido, do que não se conhece conscientemente sobre o paciente e parece estar em relação com a transferência. Assim, o paciente não se daria conta de certas coisas que estão acontecendo em sua vida e não perceberia o motivo, as circunstâncias concretas, o entorno contextual que teria provavelmente dado origem ou influenciado seu problema pessoal e de saúde mental. Interessante é lembrar que um dos modos de referir-se ao inconsciente por Mannoni (1989) é que esse constructo é definido como saber que não se sabe. De qualquer modo, fica implícito aqui que as ações do sujeito em uma primeira leitura podem aparecer absurdas ou loucas, numa segunda interpretação podem ganhar sentido se remetidas à outra trama que perpassa o sujeito, mas da qual ele não se dá conta.

Destaca-se que a dimensão do saber é também fundamental para pensar a relação dos pacientes com a equipe. Essa relação manifesta-se como campo transferencial, situação de escuta clínica, na qual o terapeuta apoia-se na transferência ocupando o lugar de suposto-saber, adotando, assim, uma estratégia onde o sujeito tenha a sua palavra, seja escutado 
na sua singularidade, e possa também escutar e apropriar-se desse discurso coconstruído. De acordo com Rosa (2006), na medida em que o profissional renuncia assumir uma posição de dominação, esse "campo permite uma relação que estrutura a produção do saber do sujeito" (p. 187), que vai sendo interpretada e pontuada para que possibilite a construção de efeitos de sentido e significações no "sujeito do desejo, engendrado pela cultura, mas que, em sua condição de dividido, pode transcender ao lugar em que é colocado e apontar na direção de seu desejo" (p.187).

Nesse sentido, o saber do terapeuta é desejado pelo paciente uma vez que o ajudaria a redimensionar sua vida. Ter suas ações definidas como psicóticas pode aprisioná-lo em uma definição alienada de si. Para a equipe, interagir entre os vários saberes profissionais de modo transferencial intersubjetivo pode fazer criar e recriar novos sentidos para os acontecimentos. A questão das diferenças entre os saberes dos técnicos que, às vezes, pode ser considerado um problema, quando subtraída dessa relação transferencial, pode ganhar outra potência, se considerarmos os jogos transferenciais intersubjetivos dos saberes.

Em relação ao surgimento da dimensão do inconsciente no atendimento ao grupo de famílias dos pacientes foi considerado haver, geralmente, por parte dessas famílias, desconhecimento em relação às doenças mentais de seus filhos e aos preconceitos associados aos mesmos. Essa falta de conhecimento, disse uma terapeuta ocupacional, tende a gerar má interpretação da enfermidade, ou do sofrimento, e isentar o paciente de qualquer responsabilidade na medida em que a família não acredita no seu potencial de recuperação e cidadania. Essa situação propicia ainda o entendimento do paciente como o culpado de tudo que ocorre na família nuclear.

Duas opiniões predominam entre os familiares, seja achando que o comportamento do paciente é estranho e intencional, seja achando que é irracional. No primeiro caso, a família tende a adotar uma atitude mais repressiva e, no segundo, uma atitude mais permissiva, fazendo, por exemplo, os gostos pessoais do paciente. Tanto em uma situação como em outra, o culpado passaria a ser uma espécie de bode expiatório, depositário das tensões grupais, conforme falou a terapeuta ocupacional.

Então, para se evitar cair no ciclo vicioso do bode expiatório, uma das questões trabalhadas no grupo de familiares é como o familiar se sente em relação a ter um membro usuário do CAPS. Nesses grupos são trabalhados os sentimentos gerados por essa situação institucional. Esses sentimentos aparecem, muitas vezes, misturados com raiva, amor, rejeição, e com algo que não pode ser dito, algo que o familiar (freqüentemente as mães) se sente impossibilitado de falar explicitamente. Quando o familiar toma consciência dessa problemática no interior das relações afetivas grupais, começa a perceber o usuário como alguém a ser acolhido e que pode ser também parceiro nas relações familiares, reconhecendo, obviamente, os limites da dinâmica familiar e a autonomia relativa dele.

Porém, acrescenta a terapeuta ocupacional anteriormente mencionada, uma outra leitura é possível, a saber: mesmo que os familiares tenham conhecimento sobre a referida problemática, pode haver uma "sobredeterminação de suas fantasias inconscientes" em relação aos fatos que levam às diferentes interpretações acerca da posição com seus parentes. Ainda, segundo essa terapeuta, os profissionais ressaltam geralmente os benefícios do uso de concepções do inconsciente para os pacientes e família, sobretudo, na medida em que evitaria o entendimento do paciente como o culpado e o descrédito no seu potencial de recuperação e cidadania.

Uma assistente social esboçou uma concepção operacional do inconsciente que seria intermediária entre o desconhecimento e o passado, referente às memórias da infância do usuário. Segundo ela, essas memórias não estão sempre presentes na sua fala, em todo caso, não se sentia capacitada para trabalhar com mecanismos psicológicos de regressão de memória. Explica que falar sobre o inconsciente é falar sobre como lidar com o inconsciente na prática. Disse ela que não sabe lidar com a regressão relativa a fatos passados, mas tenta entender a relação do presente com o passado na história de vida do usuário. Algo inconsciente ou desconhecido estaria na relação dessas duas dimensões temporais, podendo se manifestar na prática, por exemplo, por meio da repetição de certas formas de se comportar. A profissional citou o exemplo de um rapaz com uma "dinâmica psicótica", que foi violentado pelo irmão e que, depois disso, passou a ser violento com a mãe. Por meio de tarefas terapêuticas, segundo ela, esse rapaz tem a possibilidade de reorganizar seu plano de vida. Pois, nessas tarefas, ele pode ir tomando consciência de seus problemas, pouco a pouco, e ir modificando gradativamente o seu modo de organizar sua vida cotidiana.

Uma outra concepção mais difundida é a do inconsciente enquanto método para escuta do sujeito e das relações na instituição, mais presente entre os profissionais de psicologia, terapia ocupacional e psiquiatria. A instituição de formação pós-universitária em estudos psicanalíticos mais citada foi a SEDES SAPIENS em São Paulo. O foco abordado com esses profissionais girou em torno das relações terapêuticas cotidianas. Era de consenso que na coletividade terapêutica do CAPS não há o enquadre tradicional de consultório, mas sim uma prática terapêutica de rede que supõe uma implicação afetiva do profissional com o paciente em diferentes situações e atividades, por exemplo, refeições junto com ele, conversa na sala de estar, caminhadas, festas, lazer. Para uma psicóloga, apesar desse envolvimento, a leitura da transferência pode elucidar essa "contaminação" (afetiva) na rede de relações cotidianas sem necessariamente utilizar a técnica tradicional de interpretação psicanalítica. Disse ela que se trata mais de incluir na leitura da transferência outra leitura concernente às atitudes do profissional relativas à complexidade do seu lugar na instituição enquanto autoridade de saúde, mas autoridade não autoritária, que não aceita como natural ser portador de um suposto saber.

Essas atitudes se manifestam por meio de ações, condutas e decisões referentes ao ajudar, conter, suportar etc. Por outro lado, a horizontalidade na relação entre profissionais e pacientes não é entendida como pura simetria nas relações terapêuticas. A figura de autoridade permite, exemplifica a psicóloga, que o profissional adote as regras de não falar de sua vida pessoal, de manter certo distanciamento reflexivo em relação a sua atuação, com também dialogar sobre sua prática terapêutica nas reuniões diárias da equipe.

Outra afirmação da psicóloga: "o papel do profissional implica em não se identificar projetivamente com o usuário”. 
Ela explica que o atendimento terapêutico, sendo geralmente realizado por, ao menos, dois profissionais do CAPS e tendo discussões diárias de casos clínicos, é já um facilitador para evitar esse tipo de identificação. Não se refere à concepção de M. Klein sobre identificação projetiva, mas sim à ação de identificar-se a aspectos parciais e gerais do modo de ser ou de sentimentos e interpretações de outrem. Seria uma identificação por empatia no sentido literal do termo empatia: "identidade de uma pessoa com o modo de ser da outra", assim definido no minidicionário Houaiss da língua portuguesa (Houaiss, Villar, Franco, 2003). Nesse caso, o profissional não consegue diferenciar seus sentimentos e conteúdos de seus pensamentos daqueles do paciente, misturando-os com seus valores pessoais e se identificando acriticamente com o outro nessa relação. A psicóloga exemplificou esse ponto indicando o caso de um profissional que se identifica com a situação de conflito do paciente com a mãe, faz aliança com o filho e, em consequência, fica julgando a mãe com discurso moralista. Ela disse que o profissional pode ser capturado por esse tipo de identificação e citou uma situação que vivenciou, na qual o paciente era realmente cruel com seu filho. Relatou que foi muito difícil: "eu ia julgar!". Enfatizou que o mais importante é perceber esse tipo de identificação e poder refletir sobre a mesma. E para isso é fundamental haver sintonia do profissional com a equipe, a qual tem que ser respeitosa para que ele possa se expor diante dos colegas.

Nas atividades terapêuticas do grupo de verbalização, os dois coordenadores, uma psicóloga e uma terapeuta ocupacional têm uma formação de base psicodinâmica. Esse grupo trabalha a questão do "delírio psicótico". No CAPS, a situação delirante é geralmente administrada com medicação para dar suporte ao paciente e ajudá-lo nos relacionamentos com os outros. O grupo de medicação pode ser complementar ao grupo de verbalização na medida em que trabalha o significado, o uso, a importância do remédio na recuperação da saúde mental, e ainda a questão do beneficio secundário da doença. De fato, no CAPS, enfatiza-se a autonomia relativa do paciente, responsabilizando-o, na medida do possível, pela administração de sua medicação. Não se aceita manipular o paciente no sentido de enganá-lo ou forçá-lo a tomar uma medicação (e.g, colocar neurolético no suco, na comida). Ressalta a psicóloga que, no grupo de verbalização, como no CAPS em geral, o delírio não é visto no embate com a Razão, mas como via de comunicação e de entrada na relação entre profissional e usuário. A expressão verbal comunicada nesse grupo passa por uma interpretação compreensiva para ambos e associada às suas historias de vida.

O delírio é também entendido, pela psicóloga, como um tipo de mecanismo de defesa (inconsciente) do paciente para suportar o sofrimento, às vezes, da ordem do intolerável, podendo assim dar lugar a uma espécie de ruptura do Ego. E a psicóloga metaforiza dizendo que o delírio "vem montado como um sonho". Mas, essa mesma psicóloga reflete sobre uma contradição: por que há gozo em certos delírios? $\mathrm{Na}$ discussão que tivemos com outros colegas em uma reunião diária da equipe foi comentado que o delírio persecutório, com escuta de vozes e, às vezes, até acompanhado de alucinações visuais, manifestava-se geralmente com sensações dolorosas e repetitivas, bem como o delírio acompanhado de estado depressivo. O pesquisador comentou, nessa ocasião, que já tinha observado o delírio místico de um paciente evangélico, situação na qual ele se manifestava com risos e sensações de prazer, tendo esse paciente esclarecido, depois, que se sentia muito contente naquela ocasião, pois muito protegido e perto de entidades bíblicas divinas.

No grupo de verbalização, naquele período com quatro pacientes, podem participar até oito usuários que estejam com possibilidades minimamente críticas para verbalizar seu delírio e tentar dar um sentido a esse ou significá-lo. Relata a psicóloga que uma paciente acreditava estar sendo perseguida por Xuxa (apresentadora de TV) e seu chefe de trabalho, os quais estariam unidos contra ela. Sentindo-se ameaçada e parecendo enciumada, envia mensagens de cunho também perseguidor à Xuxa. Brevemente, a interpretação dessa situação remete ao grupo familiar da paciente e a mecanismos de transferência. De um lado, o "chefe" seria seu pai, "Xuxa" sua madrasta, e a paciente ameaçaria o relacionamento do casal importunando a madrasta. Quando pequena, a paciente teria sido o "xodó do pai", protegida e mimada; atualmente sentia-se insegura, ameaçada e com certo medo da atual esposa do pai.

Outro exemplo refere-se a um paciente que relatou ter visto um assalto em uma rua em São Paulo. Acredita que os bandidos o viram e consequentemente passaram a perseguilo. No delírio, o paciente menciona uma cena de abuso sexual por um desses bandidos, deixando implícito, explicou a psicóloga, a possibilidade de conflitos inconsciente relativos à homosexualidade. Em todo caso, para atenuar sua ansiedade e o medo de ser assaltado e estuprado, foi comentado no grupo de verbalização que o CAPS era um lugar que oferecia proteção dessas situações ameaçadoras. Nota-se que essa leitura do processo delirante e seu manejo consideram a dimensão inconsciente, de seu funcionamento, bem como a condição concreta da prática de rede.

No grupo de contos, qualquer tipo de paciente e qualquer profissional com horário disponível podem participar. Participam, na maioria, pacientes em tratamento que circulam pelo CAPS (em média 20). O coordenador da reunião é geralmente um psiquiatra, psicóloga ou terapeuta ocupacional. O conto é normalmente escolhido por dois desses profissionais, mas sugestões de pacientes e técnicos podem ser acatadas. O sucesso desse grupo deve-se, provavelmente, à leitura de algo mais descontraído, possibilitando um ambiente de conversa e de imaginação criativa e sem qualquer enfoque patológico. Processos inconscientes, geralmente não interpretados nessa reunião, afloram espontaneamente sob a influência dos mitos implícitos das estórias contadas. Essa implicação afetiva daria lugar à emergência da subjetividade própria de cada um, mas nem sempre compartilhada pelo grupo. A palavra do paciente é livre. Pede-se, entretanto, que ele evite contar segredos pessoais, deixando esse assunto para conversar com seus terapeutas de referência.

Aqui está um exemplo de uma dessas reuniões. O conto era sobre uma velhinha que atravessava muito uma fronteira numa lambreta e nesta levava um saco de areia. O fiscal suspeitava que ela contrabandeava alguma coisa, mas nada conseguia descobrir mesmo abrindo esse saco e a interrogando várias vezes. $\mathrm{O}$ coordenador do grupo suspende o conto alegando que o texto do fax estava ilegível, criando um certo suspense. Vários pacientes falaram e a impressão 
dada é que alguns se identificavam com o personagem da "vovozinha", outros com o do fiscal, dando suas versões próprias: que a vovozinha ia "levar areia para fazer uma casa"; que ela "botava cocaína ou maconha escondida na roupa"; que "a cocaína era colocada na areia" para se confundir com a areia; que ela "enganava o fiscal com outra coisa", deixando a suspeita no ar...; que a "vovozinha disfarçava...", frase dita com ironia, ou que "ela era mesmo contrabandista”. E, finalmente, um paciente que tinha sido fiscal há anos atrás adivinhou o motivo escrito pelo autor do conto: a "vovozinha contrabandeava a própria lambreta". Revelando o segredo, o coordenador diz sua mensagem do conto: "na vida há ocasiões que praticamos ações sem nos darmos conta". Chamava a atenção ao fato que era a lambreta que era contrabandeada, mas era o saco de areia que era visto. A partir daí, a conversação se deu sobre a parte desconhecida que existe na vida de cada um de nós.

Nesse encaminhamento do grupo pode-se dizer que estaria sendo considerada, pela menção ao desconhecido, a dimensão inconsciente. Essa dimensão desloca as concepções sobre o modo de existir das dimensões adaptativas ou morais, que desembocam no julgamento e na culpabilização, e encaminha para a dimensão da singularidade, para um modo particular de conceber o sentido da própria existência, com implicações para si, para os outros e para a modalidade de inserção social.

\section{Considerações Finais}

A análise das concepções emergentes sobre o inconsciente no cotidiano da prática terapêutica de rede de um CAPS II (adulto) paulista, fundamentada em uma pesquisa participante aí realizada, destacou três concepções: o inconsciente como inconsciência ("estar fora de si"), o inconsciente como desconhecimento e o inconsciente como método de escuta do sujeito e das relações na instituição. Pudemos constatar que essas concepções demonstram que os profissionais não se contentam apenas com as concepções racionais, morais, biológicas e/ou comportamentais da doença. Se bem que considerem criticamente esses aspectos, recorrem a concepções sobre o inconsciente atravessadas pelo cotidiano e que permitem uma pragmática conceitual mais próxima da experiência de sofrimento do usuário e familiares (Barus-Michel, 2004) e das intervenções e atividades terapêuticas diversas.

As concepções identificadas no CAPS II não apareciam nem nas reuniões de equipe, nem nas conversações cotidianas, de forma explícita ou que suscitasse reflexões aprofundadas entre os profissionais. Nosso trabalho de pesquisa contribuiu para torná-las explícitas por meio de conversações que permitiram a elaboração de notas de campo que foram aperfeiçoadas após leitura e discussão das mesmas com os profissionais do CAPS. Esses momentos de reflexão possibilitaram um movimento de mútua aprendizagem e debate entre o saber oral em construção na prática (Jesus, 2003) e o saber escrito sobre as concepções referentes ao inconsciente em forma de texto provisório.

Essas reflexões sobre o inconsciente permitiram perceber o quanto vários profissionais começaram a se dar conta da circulação de concepções que não coincidiam, muitas vezes, com conceitos clássicos e que se tratava também de uma forma de construção de saberes clínicos que se fazia a partir da tradição oral, conhecimento prático que estava sendo construído pela própria equipe terapêutica e, provavelmente, em outros CAPS. A explicitação desse conhecimento oral possibilitou mostrar a emergência de contradições, contornos, dribles conceituais que apareceram como uma espécie de tática para tentar operacionalizar ou rever certas teorizações que não mais se adequavam ao contexto do CAPS.

Podemos inferir que, nessa prática terapêutica em rede social, a dimensão do inconsciente implica a suposição de que não há uma verdade única, originária ou mesmo oculta sobre o tema. Ao contrário, pensar em termos de rede produtora de sentidos é entender, por um lado, que existem várias vias de acesso à verdade $\mathrm{e}$, por outro, que existem várias verdades. Assim, o trabalho terapêutico não é o de aplicação vertical de saberes técnicos, mas essencialmente de fazer circular a palavra, permitir a produção e explicitação de idéias e fantasias que podem ser relançadas, e estabelecer novos nexos de sentido.

A horizontalidade nas relações terapêuticas tende a garantir as especificidades das leituras sobre o inconsciente e que essas interpretações não sejam utilizadas como via de ocultação das relações de poder e de conflitos. A implicação de cada sujeito, com sua leitura do processo inconsciente, supõe a responsabilização por sua verdade, marcando assim sua posição de poder em cooperação nas relações. Posição que, em vez de formar hierarquias ou competições sobre a verdade das situações que se apresentam no cotidiano, propicia laços transferenciais que fazem circular os saberes existentes, produzindo novos saberes e novas relações.

Estimular o desenvolvimento da clínica em saúde mental e em rede social na atenção psicossocial é também promover ocasiões e atividades na instituição que possibilitem a compreensão da dimensão humana do inconsciente, principalmente por intermédio da dimensão do laço com o outro nas redes sociais. Esse laço é marcado pela condição desejante, entendida numa dialética entre o desconhecimento e o reconhecimento, o pensar e o agir, a inclusão e exclusão social.

As reflexões dos profissionais do CAPS advindas dessa pesquisa caminham no sentido de aperfeiçoar essa clínica que pratica a escuta do outro, em situação sociocultural, escuta de sua demanda de ajuda, de sua subjetividade, historicidade e condições concretas existenciais. Leituras do inconsciente podem emergir, por exemplo, a partir do desconhecimento, do não-dito, do incompreensível, em relação à subjetividade de quem sofre, de quem adoece, de quem se encontra em situação de crise existencial e assim por adiante.

\section{Referências}

Barreto, J. (2005). O umbico da reforma psiquiátrica. Cidadania e avaliação de qualidade em saúde mental. Juiz de Fora: EDUFJF.

Barus-Michel, J. (1997). Clinique du social. Bulletin $d u$ Laboratoire de Psychologie Clinique - Université Paris VII, 25, 5-9.

Barus-Michel, J. (2004). Souffrance, sens et croyance. L'effet thérapeutique. Paris: Eres.

Barus-Michel, J. (1991). Pouvoir: mythe et realité. Paris: Klincksieck. 
Freud, S. (1976). A interpretação de sonhos. Edição standard brasileira das obras completas de Sigmund Freud, Vols. IV e V ( W. I. Oliveira, Trad.). Rio de Janeiro: Imago. (Trabalho original publicado em 1900)

Jesus, R. de F. de (2003). História oral - da prática da pesquisa à pratica docente: uma opção epistemológica. Em R. L. Garcia (Org.), Método: pesquisa com o cotidiano (pp. 141-156). Rio de Janeiro: DP\&A.

Houaiss, A., Villar, M. S., \& Franco, F. M. M. (2003). Minidicionário Houaiss da língua portuguesa. Rio de Janeiro: Objetiva.

Mannoni, M. (1989). Um saber que não se sabe: a experiência analitica (M. P. Silva, Trad.). Campinas: Papirus. (Trabalho original publicado em 1985)

Perez, C. L. V. (2003). Cotidiano: história(s), memória e narrativa. Uma experiência de formação continuada de professoras alfabetizadas. Em R. L. Garcia (Org.), Método: pesquisa com o cotidiano (pp. 97-118). Rio de Janeiro: DP\&A.

Rosa, M. D.(2006). Uma escuta psicanalítica de jovens de periferia. Em S. Altoé (Org.), A Lei e as leis (pp. 183-194). Rio de Janeiro: Revinter.

Rosa, M. D., Carignato, T., \& Berta, S. L. (2006). Etica e política: a psicanálise diante da realidade, dos ideais e das violências contemporâneas. Ágora: Estudos em Teoria Psicanalítica, 9, 35-48.
Stevenson, R. L. (2003). Strange case of Dr. Jekyll and Mr. Hyde. New York: Norton.

Vieira Filho, N. G., \& Nóbrega, S. M. (2004). A atenção psicossocial em saúde mental: contribuição teórica para o trabalho terapêutico em rede social. Estudos de Psicologia (Natal), 9, 373 379.

Vieira Filho, N. G. (2006). Análise da prática terapêutica em rede social: desconstrução e atenção básica de saúde/ saúde mental. Relatório de Pesquisa de Pós-Doutorado, Universidade de São Paulo, São Paulo.
Recebido em 15.10 .06

Primeira decisão editorial em 29.01.08

Versão final em 28.02 .08

Aceito em 10.03.10 